\title{
A Tangible Platform for Mixing and Remixing Narratives
}

\author{
Cristina Sylla ${ }^{1}$, Sérgio Gonçalves ${ }^{1}$, Paulo Brito ${ }^{1}$, Pedro Branco $^{2}$, Clara Coutinho ${ }^{3}$ \\ 'engageLab/CIEd, University of Minho, Portugal \\ \{sylla, sgoncalves, pbrito\} @engagelab.org \\ ${ }^{2}$ Department of Information Systems, University of Minho; Portugal \\ pbranco@dsi.uminho.pt \\ ${ }^{3}$ Institute of Education, University of Minho; Portugal \\ ccoutinhodie.uminho.pt
}

\begin{abstract}
This work discusses a tangible interface for storytelling that targets pre-school children and offers a playful experimental space where children can create their own narratives by placing tangible picture-blocks on an electronic board. We present the system and report on the findings, describing the extent to which this interface can motivate and engage children, both in creating narratives, as well as in experimenting different solutions to solve conflicts created during the story plot.
\end{abstract}

Keywords: Tangible Interfaces, Storytelling, Oral Expression, Emergent Literacy, Collaboration, Children.

\section{The Importance of Exploring Narratives}

Storytelling plays a major role in children's lives, offering them a universe where their most adventurous fantasies become true, providing opportunities for social interaction and innovative thinking [5]. The familiarity of stories may facilitate creativity and generation of ideas helping children practice important literacy skills, such as language development, story comprehension and sense of the structure [4]. In the platform presented here, children have the possibility of animating the stories they know, or remixing elements from familiar stories, playing with characters, and objects and exploring different storylines. The interface was developed following an iterative participatory design process [2] together with preschoolers and their teachers.

\section{An Interface for Remixing Narratives}

The system is composed by different sets of picture-blocks and an electronic board that identifies the blocks placed on it. The blocks are placed on slots marked on the board. Each block has an image of what it represents on the upper side and an electronic tag on its backside that provides the system its identification. The electronic board is connected to a computer. Placing a block on the board displays the image and 
triggers an animation on the computer screen according to the combination of blocks that are on the board.

Taking into account results and observations from previous studies [6] the system animates the elements on the screen following the order in which the picture-blocks are placed, and not their position on the board. When a block is removed from the platform it just disappears from the screen (fig.1).

The story engine was implemented to animate the elements according to the rules devised from situations that typically arise in traditional children stories. As the animations play, children can add or remove elements further developing the narrative. For example, how can children help the little pig to escape from the witch? Maybe they decide to place a house where the little pig can hide, hum... or ask other characters for help? Maybe the fairy... but will she be able to defeat the bad witch?

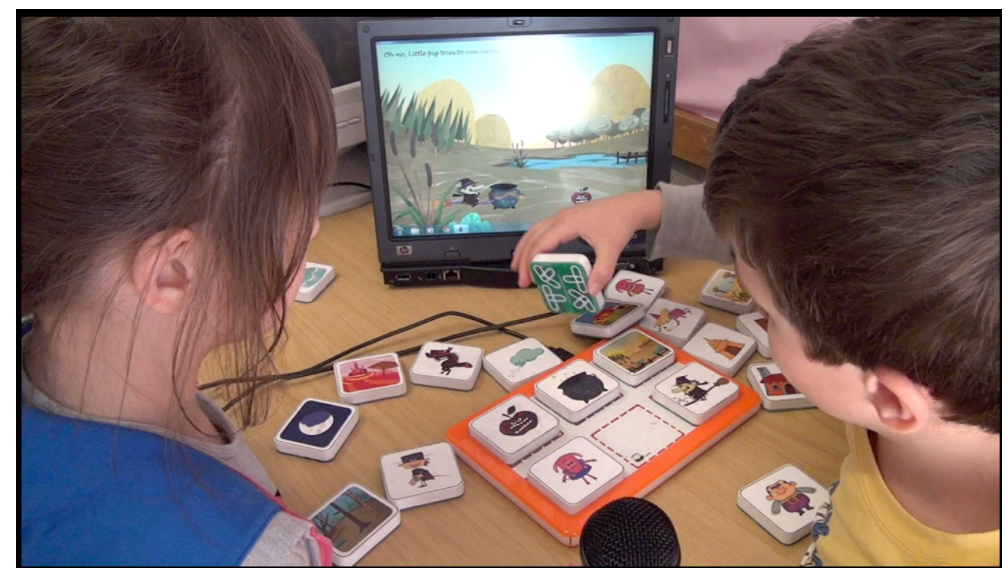

Fig. 1. Children creating a narrative

\subsection{Story Engine}

The concept behind the story engine was to model a world that would be understandable for young children. The goal is to allow children to bring their knowledge into play, while fostering their curiosity by playing out different situations where they might want to figure out what would happen if...

The story engine is implemented on top of the Unity game engine and it is developed based on behavior trees, a concept well known in the field of computer games to model character behavior, reactive decision-making and control of virtual characters. Each entity on the scene has a corresponding behavior tree that defines the actions of that element. When the users place the blocks on the platform, the behavior tree gets the inputs of the entities that are present. The behavior triggered for each entity depends on the other entities that are also in the scene, and the properties of those entities.

Adittionally, by pressing the Enter Key, the system automatically generates snapshots of the created narrative, saving them as digital images. 


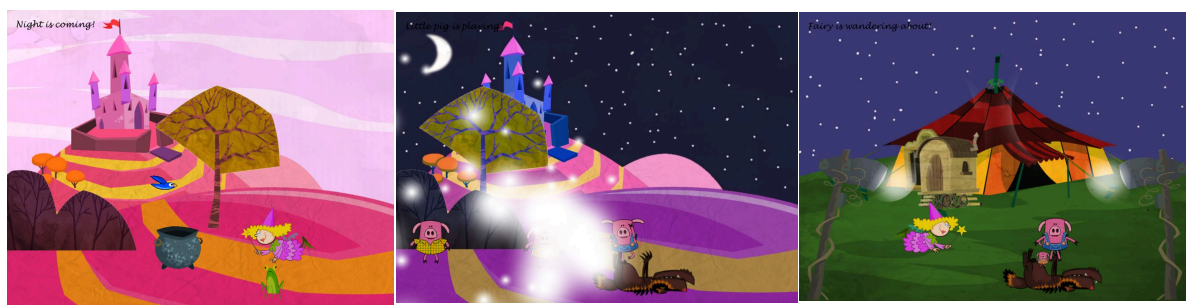

Fig. 2. Automatically generated snapshots of a narrative

The created images, which resemble comic book representations, are stored on the computer and can be directly uploaded to a blog or printed and shared with family and friends, thus extending the way to share stories with other people involving them into a collaborative storytelling experience (fig. 2).

\section{$3 \quad$ First Pilot User Study}

A qualitative user study was carried with a group of 15 children, during four sessions, with the duration of one-hour and a half each. The study revealed that one of the strongest affordances of the platform is the extent to which it promoted collaboration, showing that the children were highly motivated to engage and collaborate in different storytelling activities, exploring different story plots (fig. 3).
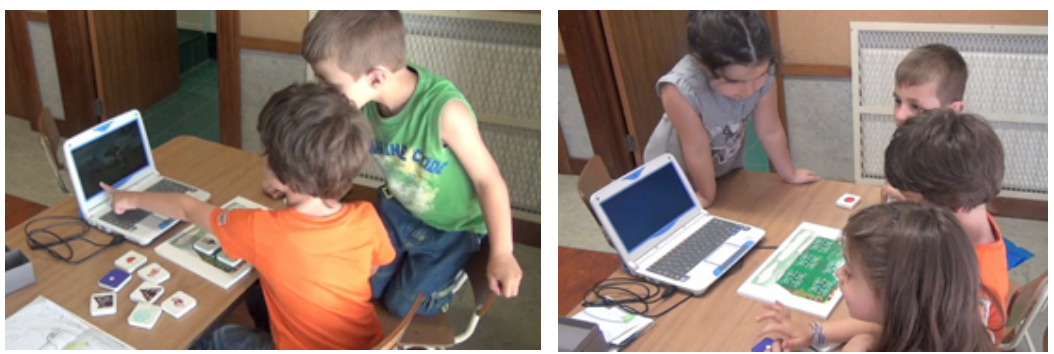

Fig. 3. Children collaborating in the creation of a story

Children engaged in teamwork, collaborating together in the creation of different stories, they personalized the figures giving them names and character traits. The tangible blocks acted as anchors for the creative process, helping children to shape their ideas. Children were able to begin their stories by situating them on particular sceneries; they used characters and created moments of tension, involving fights and the resolution of upcoming conflicts. Children explicitly expressed the wish to create their narratives with their peers, stating that it would be "more fun". The children quickly understood and used the various mechanisms behind the blocks, applying different strategies to achieve a certain goal, such as using a particular combination of blocks, or removing others. 
In line with [3] the tangibility of the input literally placed the story in children's own hands, so they negotiated, divided, and shared the blocks among them.

\section{Conclusions and Future Development}

By engaging with each other focusing on creating stories together, children may develop interpersonal language use, as they externalize their feelings and thoughts, learning to express themselves and to communicate with others, with time becoming more fluent in their language use [1]. The interaction and collaboration supported by the system creates a micro-world where children socialize with each other, learning to share, handle, divide, respect and accept the opinions from each other.

Future development involves a version to run on tablets connecting via Bluetooth, as well as to broaden and diversify different stets of blocks that explore other themes.

Acknowledgments. A very special Thank You to Colégio Teresiano, Braga the preschool children and teachers. This work is funded by FEDER funds through the Operational Competitiveness Factors Program - COMPETE and by National Funds through the FCT - Portuguese Foundation for the Science and the Technology within the Projects: PTDC/CPE-CED/110417/2009, FCOMP-01-0124-FEDER-022674 and the Doctoral Grant: SFRH /BD/62531/2009.

\section{References}

1. Ackermann, E.: Constructing Knowledge and Transforming the World. A learning zone of one's own: Sharing representations and flow in collaborative learning environments. In: Tokoro, M., Steels, L. (eds.), pp. 15-37, IOS Press, Amsterdam, Berlin, Oxford, Tokyo, Washington, (2004).

2. Druin, A.: Cooperative inquiry: Developing new technologies for children with children. In: Proceedings of CHI'99, International Conference on Human Factors in Computing Systems, pp. 592-599, ACM Press, New York (1999).

3. Hunter, S., Kalanithi, J., Merrill, D.: Make a Riddle and TeleStory: Designing Children's Applications for the Siftables Platform. In: Proceedings of IDC'10 International Conference of Interaction Design and Children, pp. 206-209, ACM Press, New York (2010).

4. Morrow, L. M.: Literacy development in the early years: Helping children read and write (5th ed.), Allyn and Bacon, Boston (2005).

5. Paley, V.G.A.: Child's Work: The Importance of Fantasy Play. Chicago University Press, Chicago (2004).

6. Sylla, C., Branco, P., Coutinho, C., Coquet, M.E., Škaroupka D.: TOK - a Tangible Interface for Storytelling. In: Proceedings of CHI'11, International Conference on Human Factors in Computing Systems, pp. 1363-1368, ACM Press, (2011), DOI: $10.1145 / 1979742.1979775$. 